\title{
Letrônica
}

\section{Tradução literária e as reflexões de Hilaire Belloc sobre a arte de traduzir}

\section{Literary translation and reflections on the art of translating by Hilaire Belloc}

Mestranda em Estudos da Tradução pela Universidade de São Paulo. Possui licenciatura em (2006) e especialização em Psicopedagogia pela Universidade Nove de Julho (2011). Tem experiência na area de Letras, com ênfase em Lingua Portuguesa, Lingua Inglesa e suas foi rellizado titeraturas. Aperfeicomento de Pessoal de Nivel Superier Brasil (CAPES) - Código de Financiamento 001. (ii)_http://orcid.org/0000-0002-5339-8919 E-mail: ferri_leticia@hotmail.com
Letícia Mendes Ferri ${ }^{1}$

Universidade de São Paulo, Faculdade de Filosofia, Letras e Ciências Humanas, Programa de Pós-Graduação em Estudos da Tradução, São Paulo, SP, Brasil.

\section{RESUMO}

Os estudos da tradução vêm ganhando cada vez mais espaço no campo da pesquisa acadêmica e as teorias e concepções acerca da definição ou do significado de tradução ainda divergem entre os autores, além disso, a definição de tradução tem sofrido mudanças ao longo dos anos. Alguns teóricos costumam dividi-la em dois tipos: tradução literária e tradução não literária. Este estudo tem por objetivo investigar as diferentes concepções teóricas sobre tradução e as considerações de diversos autores acerca desse tema, sobretudo tradução literária. Ademais, serão apresentadas as reflexões de Hilaire Belloc, um dos mais diversificados autores na história da literatura inglesa, sobre tradução geral e tradução literária em prosa e em verso.

Palavras-chave: Tradução literária. Hilaire Belloc. On Translation.

\section{ABSTRACT}

Translation studies have been gaining more visibility in the field of academic research. Theories and conceptions about the definition or meaning of translation still diverge among the authors, in addition, the definition of translation has undergone changes over the years. Some theorists usually divide the translation into two types: literary translation and non-literary translation. This study aims to investigate the different theoretical conceptions about translation and the considerations of several authors about this subject, especially literary translation. In addition, it will highlight the reflections of Hilaire Belloc, one of the most diverse authors in the history of English literature, about general and literary translation in prose and verse.

Keywords: Literary translation. Hilaire Belloc. On Translation. 


\section{Introdução}

— mbora não seja objetivo deste estudo discutir em profundidade I os problemas pertinentes à atividade de tradução em geral, faz-se necessário situar, mesmo que brevemente, o complexo tema da tradução literária dentro do contexto geral da tradução.

Nunca se discutiu e se pesquisou tanto a atividade de tradução como nos últimos tempos. Porém, as teorias e concepções divergem desde a alegação da impossibilidade teórica da tradução até o princípio de que tudo pode ser perfeitamente traduzível.

De acordo com a etimologia, traduzir (do latim, trans + ducere) significa levar através de. O verbo levar (duco) é transitivo. Nesse caso a reflexão seria: O que se leva? Ademais, a partir dessa reflexão, sugerem-se outras questões de natureza circunstancial, como por exemplo: De onde? Para onde?

Dar uma definição exata ou o significado de tradução não é uma tarefa fácil. Além disso, esse conceito tem sofrido mudanças ao longo dos anos. O conhecido ditado italiano parafraseado pelo filósofo Benedetto Croce, Traduttore-traditore ${ }^{1}$, declara que a falsificação é inevitável na tradução e que o tradutor é um traidor, um falsificador do original. Similarmente, a própria instituição da tradução foi desprezada com a seguinte comparação, que pode ser considerada preconceituosa: "A tradução é como uma mulher, se bela não pode ser fiel, se fiel não pode ser bela"2 (Anon, citado em KRISHNASWAMY et al., 1992, p. 235, tradução nossa).

Catford define tradução do ponto de vista da linguística: "A tradução pode ser definida da seguinte forma: a substituição do texto em uma língua

\footnotetext{
1 "Tradutor-traidor" (tradução nossa)

Do original: Translation is like woman if beautiful, it cannot be faithful and if faithful, it cannot be beautiful.
}

(Língua Fonte) para um texto equivalente em outra língua"3 (CATFORD, 1965, p. 20, tradução nossa). Além disso, Catford aponta os desafios que podem ser encontrados na tradução de certas palavras e ressalta a necessidade de definir a natureza do texto para manter a tradução fiel. Para o autor: "0 problema central da prática de tradução é encontrar termos equivalentes na língua de chegada. Uma tarefa central da teoria da tradução é definir a natureza e a condição de uma tradução equivalente"4 (CATFORD, 1965, p. 21, tradução nossa).

Para Das (2008), o tradutor deve possuir uma fluência completamente natural nas duas línguas, deve ter uma intimidade com ambas a ponto de as palavras fluírem instintivamente. A tradução não deve ser mecânica, cada palavra está dentro de um contexto e contém um sentido interligado com todo o texto. Para enfatizar esse ponto o autor usa uma citação de Meenakshi Mukherjee: "O tradutor é um escritor na língua para a qual está traduzindo, isto é, seu manuseio da língua não é meramente competente, mas também criativo"5 (MUKHRJEE, 1981, apud DAS, 2008, p. 6, tradução nossa).

Alguns teóricos costumam dividir a tradução em dois tipos: literária e não literária. Wellworth (1987, p.143) sugere que uma tradução literária deve recriar a mensagem em um contexto cultural similar à língua original. Sendo assim, ao traduzir um texto literário, o tradutor decodifica o significado do texto na língua de origem e o recodifica na tradução.

Sir John Denham (1615-1669), em seus comentários sobre a arte de traduzir poesia, aponta que a tradução literal deixa de conter qualquer tipo de vital calor, não podendo, dessa forma, restaurar o espírito vital.

3 Do original: Translation may be defined as follows: the replacement of textual material in one language (SL) by equivalent material in another language.

${ }_{4}$ Do original: The central problem of translation-practice is that of finding TL translation equivalents. A central task of translation theory is that of defining the nature and condition of translation equivalence. al: The translator is a writer in the language in which he is translating, that is, his handling of the language is not merely competent but creative. 
Esse tipo de tradução, segundo o autor, é mais apropriado para os assuntos relacionados aos fatos ou à fé.

A responsabilidade do tradutor de poesia não é a de "traduzir de uma língua para outra, mas traduzir poesia em poesia" e "a poesia é de um espírito tão sutil que, ao se derramar de uma língua para outra, tudo se evapora; e se um novo espírito não for acrescentado na transfusão, nada restará a não ser um caput mortuum" (DENHAM, 1656 apud MILTON, 1993, p. 25).

John Dryden, figura de grande influência no mundo das letras na Inglaterra na segunda metade do século XVII, expôs comentários consideráveis acerca da tradução de poesia nesse período. Dryden adverte que "é quase impossível, ao mesmo tempo, traduzir literalmente e bem". Esse tipo de tradução é, para ele, como "dançar em uma corda com as pernas agrilhoadas":

[...] dançar em uma corda com as pernas agrilhoadas: pode-se evitar uma queda sendo-se cauteloso; mas não se pode esperar que os movimentos sejam elegantes: e, na melhor das hipóteses, não passa de uma tola tarefa, pois nenhuma pessoa sensata se exporia ao perigo em troca dos aplausos por ter escapado sem quebrar o pescoço (DRYDEN, 1956, apud MILTON, 1993, p. 27).

Para Dryden, o tradutor deve tentar aproximar o seu estilo do estilo do original, deve, também, familiarizar-se com as características do seu autor e tentar associar-se a ele, "conformar o nosso gênero ao dele, dar ao seu pensamento o mesmo toque", o que, segundo ele, não é tarefa sempre fácil.

Muitas vezes, a tradução de uma bela expressão pode produzir um resultado pouco atraente, e que, nesse caso, o tradutor pode ser levado a escolher outra expressão que não destrua o sentido. Além disso, considera que as palavras e linhas não precisam ficar confinadas à métrica do seu original, mas adverte que o tradutor não deve mudar o significado dado pelo autor.

A preocupação em relação ao trabalho do tradutor não é algo contemporâneo. É possível observar essa inquietação nos pensadores da Idade Média. Leonardo Bruni, já nesse período, declarava:

Enfim, os vícios do tradutor são: compreender mal o que deve ser vertido, ou vertê-lo mal, ou transformar o que disse o autor primeiro de forma apropriada e harmônica de maneira que apareça inadequado, desarmônico e sem graça (BRUNI, 1426 apud FURLAN, 2006, p. 59).

É possível perceber na declaração do humanista Aretino que a tradução, já naquela época, era considerada uma arte ou um ofício de grande responsabilidade. Praticamente dois séculos depois, a título de exemplo, Thomas Sébillet reforça esse pensamento ao declarar que "realmente, merecem grande louvor a obra e aquele que conseguiu de maneira precisa e fiel expressar em sua língua o que o outro escreveu melhor na dele, depois de tê-lo bem concebido em seu espírito" (SÉBILLET, 1548, apud FURLAN, 2006, p. 293). Dessa forma, entende-se que realizar o trabalho de tradução requer certa competência por parte do tradutor e que tal atividade é digna de honras.

Reiss e Vermeer (1984, apud NORD,1991) propõem uma noção de tradução em que se utiliza o princípio da funcionalidade, o modo como uma tradução deve ser feita dependerá diretamente do encargo tradutório a ela associado. Assim, a noção de equivalência, cujo princípio fundamental consiste na premissa de que texto de partida e texto de chegada devem ser equivalentes, se apresenta apenas como uma das possibilidades do encargo tradutório.

Essa mudança de paradigma proposta pelos funcionalistas representou um grande impacto nos estudos da tradução em relação ao conceito de tradução que até então estava sendo utilizado. 
Vermeer (1986 apud Nord, 1991, p. 11) também desloca a noção de tradução, até então considerada um processo essencialmente linguístico, para um processo, sobretudo cultural, uma vez que, para o teórico, o ato de traduzir é uma ação humana, dotada de propósitos e intenções, e inevitavelmente inserida em um sistema cultural repleto de particularidades. Skopos é uma palavra de origem grega ( $\sigma \kappa o \pi o ́ \varsigma)$ que significa propósito, daí deriva a teoria de escopo (em alemão Skopostheorie) na tradução, inserida por Vermeer, à qual todo processo tradutório deve submeter-se.

Christiane Nord (1991) sistematiza as ideias dos funcionalistas Hans J. Vermeer e Katharina Reiss, propondo um modelo, destinado à formação de tradutores e à aplicação no processo tradutório em si, tendo por base as premissas funcionalistas.

0 funcionalismo contempla a tradução como uma comunicação intercultural, na qual texto de partida e texto de chegada pertencem a sistemas culturais distintos, e por isso suas funções devem ser analisadas separadamente e de maneira pragmática, levando em consideração, sobretudo a situação de recepção de cada um dos textos. Com efeito, os receptores dos textos de partida e chegada são, indubitavelmente, um dos princípios determinantes do escopo da tradução, visto que um texto é um ato comunicativo que só se completará no momento da recepção. Sob esse aspecto, o tradutor é um produtor de texto que, munido das intenções do produtor de texto da cultura de partida, produz, na cultura de chegada, um novo instrumento comunicativo (NORD, 1991, p. 11).

Conforme apontado por Christiane Nord, o que condiciona o processo de tradução é a finalidade à qual é dirigida a ação tradutória, que se configura pela sua intencionalidade, uma das características que define qualquer ação. Nesse sentido, a função de uma tradução resulta de fatores associados ao seu público leitor, levando em conta seu conhecimento, suas expectativas, seus valores, que consequentemente estão relacionados à cultura em que se encontram.
A tradução geralmente ocupa uma posição periférica em relação ao texto original, ocupando constantemente o centro de atenção crítica. A arte de tradução restrita a uma concepção de renderização de um texto de partida para um texto de chegada, de forma que se assegure seu significado e sua estrutura o mais próximo possível do original, mas sem que se alterem as estruturas da língua de partida é resultado do baixo status atribuído à tradução. Além disso, frequentemente são feitas distinções entre o escritor e o tradutor, em detrimento desse último.

A esse respeito, Hilaire Belloc (1931, p. 4) observa: "A arte de tradução é uma arte subsidiária e derivada. Por esse motivo, nunca foi atribuída ao texto traduzido a dignidade do trabalho original".

Fatores textuais que se prendem à natureza do texto, ao seu modo de significar, são, muitas vezes, decisivos na discussão sobre tradutibilidade. Textos considerados veiculares, chamados objetivos, em que o significado é o que realmente importa, a língua intervém neles como uma simples base para a comunicação de um conceito, de um procedimento, de um fato. É o caso de teoremas matemáticos, de um procedimento cirúrgico, do enunciado científico, etc. Nessa categoria, os textos têm compromisso com a clareza e com a racionalidade objetiva, e sua intradutibilidade relativa geralmente é considerada zero. Os problemas enfrentados na tradução, quando existem, envolvem questões de terminologias e normalmente há solução.

Em outros textos, no entanto, a língua não é um mero suporte, mas parte integrante da própria mensagem, o significante predomina sobre o significado. É o que chamamos tradicionalmente de textos literários. Para esses textos, a discussão sobre tradutibilidade torna-se pertinente, especialmente no que diz respeito ao verso e ao ritmo, manifestações características da poesia.

Partidários da intradutibilidade da poesia baseiam-se em concepções de oposição entre conteúdo e forma, autor e tradutor, atribuindo superioridade 
do texto original em relação à tradução. Assim, a tradução arruinaria a própria natureza do original, a sua essência, sendo, portanto, impossível.

Essa visão dualista fica evidente nos comentários de Melchior de Vogüé:

Os poetas russos não são e não serão jamais traduzidos. Um poema é um ser vivo, de uma vida furtiva que reside no arranjo das palavras; não se transporta essa vida para um corpo estranho. Eu lia uma tradução russa muito exata e aceitável das Noites de Musset, e ela me dava o mesmo prazer que pode produzir o cadáver de uma bela criatura. A alma tinha desertado, o aroma que constitui todo o valor dessas sílabas evaporara-se. 0 problema é ainda mais insolúvel quando a versão se opera do idioma mais suave da Europa (o russo) para o menos de todos (o francês) (VOGÜÉ, 1886 apud LARANJEIRA, 1993, p. 25).

Essas afirmações correspondem ao pensamento de que não é possível a tradutibilidade de poesia. A tradução poderia ser considerada correta, aceitável, mas sem alma. O conteúdo pode ser traduzido, levado de uma língua para outra, mas a forma, a alma, essa evapora-se, e, com ela, a poesia. Ademais, percebe-se nessas colocações, que existem línguas mais poéticas do que outras, essa afirmação apoia-se em uma visão patriótica que não sobrevive à análise.

Esse dualismo ideológico conteúdo/forma enquanto fonte de intradutibilidade tenta ser justificado, igualmente, de uma maneira mais científica, conforme se observa nas afirmações de Jean Cohen:

O tradutor nunca trai os textos, a não ser os literários. A tradutibilidade talvez seja justamente o critério que permite a diferenciação dos dois tipos de textos. Este é um fato de que a máquina de traduzir dá testemunho. E todo o problema está em saber qual é a fonte da intradutibilidade poética [...] A tradução substancial é possível; só não o é a tradução formal. [...] Tanto assim que do poema só se pode conservar o sentido (na sua substância), perdendo-se a forma e, pelo fato mesmo, a poesia (COHEN, 1966, apud LARANJEIRA, 1993, p. 26).
Jean Cohen aponta a incapacidade da máquina de traduzir poesia, o que pode ser considerada uma afirmação incontestável, mas essa impotência do computador diante dessa tarefa apenas nos mostra que o processo de significação da poesia é diferente do da linguagem veicular, mas ainda assim não prova a intradutibilidade da poesia.

Hilaire Belloc considera que a tradução poética deve procurar alcançar um efeito espiritual. 0 tradutor que se empenha em traduzir poesia deve procurar dar ao texto o mesmo efeito, visando alcançar o "espírito" do texto original. O autor publicou On Translation (Taylorian Lecture, Oxford, 1931) em que trata de questões de tradutologia geral e literária. As reflexões de Belloc acerca do trabalho de tradução serão apresentadas na seção 3 deste estudo.

\section{Hilaire Belloc}

Joseph Hilaire Pierre René Belloc nasceu na França, em La Celle, próximo a Paris, em 27 de julho 1870 e morreu em 16 de julho 1953, aos 82 anos, em Guildford, Surrey. Filho do francês Louis Swanton Belloc, um advogado conhecido por toda França, casado com a inglesa Bessie Rayner Parkes. Sua mãe, que viveu até os noventa e cinco anos, era uma mulher intelectual, considerada uma das mais proeminentes feministas inglesas e defensoras dos direitos das mulheres na época vitoriana. Era também poeta, ensaísta e jornalista.

Com a morte de seu pai, quando ainda tinha dois anos, sua mãe decidiu retornar à Inglaterra, onde o autor cresceu e passou a maior parte de sua vida. Sua educação foi quase inteiramente britânica, começando na Oratory School, em Birmingham, uma escola católica, e continuando no Balliol College, em Oxford, pelo qual se licenciou em História, em 1894, com "as mais altas honras". Era conhecido como escritor, orador, poeta, homem das 
letras, soldado, marinheiro e ativista político. Foi presidente da União em Oxford e mais tarde membro do parlamento em Salford de 1906 a 1910.

Casou-se com a americana Elodie Hogan, em 1896. Em 1906, ele comprou terras e uma casa, chamada King's Land, em Shipley, West Sussex, um condado no sudeste da Inglaterra, onde criou sua família e viveu até pouco antes de sua morte. Elodie e Belloc tiveram cinco filhos antes de sua morte por gripe em 1914. Após sua morte, Belloc manteve o luto pelo resto de sua vida, conservando seu quarto exatamente como ela o havia deixado.

No período entre 1906 e 1910 foi membro do Partido Liberal do Parlamento Britânico. Seu primeiro discurso na Câmara, no início de 1906, ganhou uma reputação imediata como um brilhante orador. Belloc atraiu uma considerável atenção durante sua campanha e venceu as eleições.

Para Speaight (1957, p. 269, 296), Belloc revelou-se um excelente orador e poderia ter tido, se quisesse, uma carreira distinta na política, mas em 1910, desiludido com a corrupção, deixou o parlamento. Ao preferir a escrita, Belloc tornou-se um dos mais diversificados autores na história da literatura inglesa. Quando morreu, com quase 83 anos de idade, deixou cerca de cem livros publicados e um grande número de ensaios, artigos, recensões e discursos.

Hilaire Belloc era um polemista notável, crítico literário, analista social e político. Escreveu muito sobre história, embora esse campo tenha ocupado um espaço relativamente pequeno na totalidade de sua bibliografia. Seus poemas podem ser encontrados em muitas antologias de poesia inglesa.

Além da importância de seus trabalhos, é lembrado também por promover a fé católica. O autor foi altamente considerado dentro da comunidade católica e escreveu para organizações como Catholic Truth Society. Pode-se dizer que suas opiniões representavam a visão da maioria dos católicos britânicos no período entre as duas guerras mundiais. Sheed, um então respeitado líder católico, escreveu:
Mais do que qualquer outro homem, Belloc fez o mundo Católico-Britânico em que todos nós vivemos. Houve Chesterton, é claro, mas Belloc teve muita influência na realização de Chesterton, e Chesterton nem tanto em Belloc (SHEED, 1953 apud MORTON, 1955, p. 122).

Esta apreciação aponta o impacto que Belloc teve no catolicismo inglês. Morton (1955, p. 121, tradução nossa) ainda escreveu que Belloc "estava destinado a ser o campeão (herói) na Igreja Católica neste país". Dessa forma, a crítica atribuída a Belloc pode ser, de certa forma, atribuída à comunidade católica de seu tempo.

Hilaire Belloc foi acusado, muitas vezes, de ser um historiador fraco, muito agressivo em seus argumentos, um extremo antissemita e com visão limitada quanto a culturas não europeias. Tais acusações são embasadas em sua visão de fatos históricos, militância bruta, alegações antijudaicas, juntamente com sua declaração: "A fé é a Europa. A Europa é a fé"7 (BARTON, 2014, p. 2, tradução nossa).

Para Barton (2014, p.2), essas supostas falhas de Belloc contrastam com a necessidade de precisão na história, o moderno espírito ecumênico, esforços para evoluir a compreensão judaico-cristã e a necessidade da fé se expressar em culturas não europeias.

\section{On Translation}

Em On Translation, publicado em 1931 (Taylorian Lecture, Oxford), Hilaire Belloc trata de questões de tradutologia geral e tradução literária em prosa e em verso. As reflexões do autor acerca do trabalho de tradução serão apresentadas a seguir ${ }^{8}$.

\footnotetext{
6 Do original: [...] was destined to be the champion of the Catholic Church in this country.
}

8 As reflexões do autor apresentadas neste estudo são provenientes de tradução nossa. 
Segundo o autor, uma boa tradução é algo excepcionalmente difícil de alcançar (e o talento e a instrução para se chegar a ela são correspondentemente raros) porque isso demanda o que, para ele, pode ser chamado de dual control:

0 tradutor trabalha em dois meios e deve manter-se a par dos dois em todos os momentos de sua obra, eles devem estar presentes perante ele em igual peso e ainda - o que é um ponto sutil, porém essencial - perante ele de duas formas diferentes. Ele deve compreender ao mesmo tempo o que está traduzindo e produzindo, ou como eu deveria dizer, criando (BELLOC, 1931, p. 32, tradução nossa) 9 .

Para o autor, um tradutor deve conhecer bem cada um dos dois idiomas envolvidos e, para ele, esse conhecer vai muito além de um significado preciso dos termos de cada língua, uma vez que uma simples palavra que representa um determinado objeto em uma língua poderá ter uma conotação diferente da palavra correspondente em outra língua. Além disso, o tradutor deve também possuir uma intimidade com a língua de origem a ponto de a transição ser algo natural: “(...) possuir uma espécie de língua sombria, o espectro da língua composta, um misterioso idioma que combina as duas línguas, agindo como uma ponte e permitindo que ele passe continuamente de uma para a outra"10 (BELLOC, 1931, p. 32, tradução nossa). O autor considera que, além de ser importante o tradutor entender completamente aquilo que está traduzindo, ele deve escrever muito bem na língua em que traduz, de maneira que o leitor não saiba que se trata de uma tradução e sinta-se tão satisfeito como se estivesse lendo o original.

${ }^{9}$ Do original: The translator is working in two mediums, which two - he has to be keeping abreast during every moment of his work, which both have to be present before him in equal weight and yet - what is a subtle point but an essential one - present before him in two different ways. He has to be at the same a subtle point, but an essential one - present before him in two different ways. He has to be at the sanderstanding; that which he translates and producing, or as I should say actually creating.

time understanding; that which he translates and producing, or as I should say actually creating.

Do original: (...) to possess a sort of shadowy tongue, the wraith of a composite language, a mysterious

diom which combines the two, acts as a bridge, and permits him to pass continuously from one to the
A tradução, evidentemente, tem uma importante função social e, se considerarmos um campo mais amplo, podemos dizer que é uma condição de ordem entre as nações e, portanto, de paz. É a condição sem a qual uma cultura comum não poderia existir. A esse respeito, o autor chama a atenção ao fato de que, ainda que as traduções possam ser amplamente disseminadas na sociedade, se não forem bem-feitas, podem fazer mais mal do que bem (BELLOC, 1931, p. 34).

Para Belloc (1931), o tradutor pode ser guiado por regras aplicáveis ao trabalho de tradução. Ele divide essa tarefa em dois departamentos ou grupos, que correspondem a duas finalidades ou funções: a primeira que arbitrariamente chama de translation of instruction, usada para transmitir determinados fatos de uma língua para outra; e a segunda que chama de literary, com a função de uma tradução com efeito espiritual de uma língua para outra, como por exemplo, a tradução de uma grande história ou de um grande poema. Porém, ele considera que o segundo grupo é um caso particular do primeiro (BELLOC, 1931, p.34).

Em razão de o conteúdo ser diversificado na sua origem e se diversificar dentro do próprio grupo, o autor considera que para se estabelecer uma tradução correta há regras gerais que podem ser aplicáveis a todas as traduções. Dessa forma, ele aponta as regras que devem guiar o trabalho de tradução: duas que considera positivas e muito óbvias e uma terceira, que considera negativa e, portanto, mais frequentemente transgredida. As duas positivas são: 1) a tradução deve ser feita na língua do tradutor; 2) o tradutor deve dominar o mais perfeitamente possível a língua traduzida, sem confusões em sua mente. A terceira ou regra negativa afirma que: 3) o tradutor precisa estar livre de restrições mecânicas, das quais as duas principais formas são: a) restrição de espaço, b) restrição de forma.

Para Belloc (1931), a tradução fica melhor quando feita na língua do tradutor e o resultado final de uma tradução se torna a produção de uma 
obra em uma determinada língua. Somente na própria língua um homem pode escrever profícua e continuamente, utilizando-se de seus próprios artifícios para criar algo permanente. Nesse sentido, ele faz um alerta ao fato de que se o tradutor não for um bom escritor na sua própria língua, o resultado final da tradução poderá ser ruim:

[...] erros ocasionais no significado do original terão geralmente não mais do que um efeito mecânico, enquanto que uma utilização insuficiente da língua em que a tradução é feita é de considerável importância, afetando a própria essência de uma obra e ela por completo (BELLOC, 1931, p. 36, tradução nossa) ${ }^{11}$.

Quando o tradutor domina o mais perfeitamente possível o idioma original, o autor considera o fato como "obviamente uma vantagem"12, mas acredita que quando existe uma grande familiaridade por parte do tradutor com o idioma estrangeiro poderão surgir confusões em sua mente e resultar, portanto, em uma tradução ruim (BELLOC, 1931, p. 37-38, tradução nossa).

Belloc acredita que a tradução deve estar livre de restrições mecânicas de espaço e de forma. A tentativa de manter a mesma extensão da tradução em relação à extensão do original pode ser prejudicial para o resultado final da tradução. Para o autor, uma tradução deve ser, quase sempre, de maior tamanho em relação ao texto original, a menos, é claro, que se consiga uma equivalência satisfatória, o que considera uma tarefa difícil. Existem palavras que possuem dentro de si uma frase completa, um contexto específico, e pode ser que não exista uma tradução exata da palavra. Nestes casos, devemos "abrir" ou "decompor" a palavra para manter o significado

${ }^{11}$ Do original: (...) occasional errors in the meaning of the original will generally have no more than a mechanical effect, while an insufficient use of the language into which the translation is made is of mechanical effect, while an insufficient use of the language into which the translatic

12 Do original: obviously an advantage. do texto. Esta regra aplica-se particularmente com força maior em relação ao verso. Ele observa que no esforço desesperado de se traduzir linha por linha ou página por página pode-se arruinar o resultado. Assim como de espaço, não deve haver restrição de forma. 0 tradutor não precisa traduzir em um soneto um soneto, em um capítulo um capítulo e, menos ainda, em um parágrafo um parágrafo (BELLOC, 1931, p. 38-39).

De forma geral, ele acredita que, além dessas duas restrições de espaço e forma, todas as restrições mecânicas devem ser evitadas na tradução:

Não significa que se eu escolhi uma determinada forma que você deve mantê-la. Ao sentar-se para fazer uma tradução de um soneto, você não deve passar das quatorze linhas. Ao sentar-se para escrever um epitáfio, você não deve produzir uma pequena biografia (BELLOC, 1931, p. 38-39, tradução nossa) ${ }^{13}$.

Belloc enfatiza a importância da tradução como força social, particularmente em matéria de unidade espiritual entre as nações.

Em relação à tradução literária, Belloc faz uma divisão em dois departamentos particulares, a tradução em prosa e a tradução em verso. $\mathrm{Na}$ tradução em prosa, ele considera alguns pontos, os quais serão apontados a seguir.

Para o autor, o tradutor não deve se deter a sentença por sentença, menos ainda a palavra por palavra, mas sempre "blindar" o seu trabalho, ou seja, o tradutor deve primeiramente ler o material a ser traduzido em sua totalidade e, ao compreendê-lo como um todo no texto original, poderá comprometer-se com a tradução. A partir disso, quando a tradução estiver a caminho e antes de reproduzi-la em outra língua, o tradutor

${ }^{13}$ Do original: By which I do not mean that having chosen a form you must not maintain that form; having sat down to write a translation as a sonnet you must not run to fifteen lines; having sat down to write an epitaph, you must not produce a little biography. 
deve compreender ao menos seção por seção, parágrafo por parágrafo, perguntando a si mesmo antes de cada divisão, qual o sentido que ele quer transmitir, qual o efeito que a unidade pode produzir no todo. Ademais, ele faz um alerta para o uso de dicionário, uma vez que haverá ocasiões em que será necessário verificar o significado exato de uma palavra em particular, e para esse serviço o dicionário é essencial, a menos que o tradutor seja completamente bilingue, o que considera uma desvantagem para a tradução, conforme apontado anteriormente. No entanto, considera que confiar constantemente no dicionário pode ser fatal, pois essa prática indica que o tradutor não possui conhecimento suficiente do original, ou ainda, indica uma confiança insuficiente em si mesmo, o que para a tradução ou qualquer outro trabalho criativo, é um mal:

Se com a sua experiência você está seguro de que um significado particular é intencional, não tenha medo de dar esse significado, embora o dicionário não o tenha; lembre-se de que todos os dicionários são feitos por tradutores e que cada tradutor é como você, um ser imperfeito. Sua própria experiência, quando você tem certeza, é um guia suficiente (BELLOC, 1931, p. 179, tradução nossa) ${ }^{14}$.

Belloc menciona a importância de interpretar idioma por idioma. Idiomas com natureza própria demandam uma tradução em uma forma diferente do original. 0 autor exemplifica com o termo grego By the Dog', que se traduzido literalmente para o inglês, muda o sentido da expressão para o novo público. A expressão mais próxima do sentido pretendido seria By God!, que mantém o significado e a mensagem do original, permitindo que o público da língua de chegada compreenda o objetivo da mensagem.

${ }^{14}$ Do original: If you are fairly certain from your experience that a particular meaning is intended do not fear to give that meaning although the dictionary has it not; for remember that all dictionaries are made by translators and that every translator is like yourself, an imperfect being. Your own experience, when you are sure of it, is a sufficient guide.
Belloc também menciona que em francês pode-se usar a interrogação não apenas em perguntas, mas também para regular a prosa. Sendo assim, a sentença Que demanda-t-il? Demandat-il une solution financière ou une solution politique? Il demanda bien une solution financière, mais une solution financière subordonnée à la solution politique não poderia ser traduzida dessa forma: "E qual seria seu objetivo? Ele estava considerando uma solução financeira ou política?", o correto seria: "A solução que ele estava procurando era essencialmente política, apesar de existir um elemento financeiro nela, estava abaixo de seu objetivo político". Belloc também aponta a sentença sem verbo, natural no idioma francês, mas não no inglês. A sentença sem verbo pode ser usada e, às vezes, deve ser usada no inglês, mas raramente e com muito cuidado. Isto é contundente apenas porque é incomum, mas no francês é algo frequente.

Segundo o autor, ao se traduzir uma frase, é preciso processar intenção por intenção e uma negligência nessa regra pode levar a resultados equivocados. A intenção de uma frase em determinado idioma pode ser menos enfática do que a forma em que ela se apresenta na frase, ou pode ser menos. Ela tende a inclinar um pouco mais para um lado ou para outro, e ao traduzir uma frase para outro idioma, é preciso considerar se a forma habitualmente usada na língua de chegada tende mais para um ou para o outro lado. Um escritor político, por exemplo, ao falar sobre alguma lei que ele desaprova, dirá Voici ce qui a perdu le pays. Se essa frase for traduzida em "Isso é o que destruiu o país" perderá da intenção da frase original. 0 propósito da frase em francês não é dizer que o país foi destruído pela lei, mas que foi "ferido", "enfraquecido". Uma tradução que estaria mais próxima da intenção do original seria "Esta lei trouxe consequências graves para o país". Na tentativa de traduzir intenção por intenção, em conformidade com a língua de chegada, frequentemente serão acrescentadas palavras que não constam no texto original. 
Ainda sobre a tradução em prosa, Belloc (1931) chama atenção para as palavras com forma semelhante nas duas línguas, aquela da qual estamos traduzindo e aquela para a qual estamos traduzindo. Com o passar do tempo, uma palavra pode mudar de significado e manter a mesma forma. Uma das palavras mais óbvias é deception, que em francês significa decepção e em inglês, engano. Outro caso, talvez não tão conhecido, é o entrelaçamento entre magistrate e judge. Em francês, a antiga palavra significa o maior cargo, em inglês, o menor.

Belloc recomenda ao tradutor a "transmutar de forma ousada", de forma que transmita o sentido da mensagem sem se preocupar com as dificuldades verbais. $\mathrm{O}$ autor reforça que, na tentativa de encontrar um sentido correspondente, o tradutor não deve temer ampliar a obra. Como exemplo, cita a palavra em francês constater que normalmente é traduzida por sentenças completas em inglês como We note without further comment ${ }^{15}$, ou We note for purposes of future reference ${ }^{16}$, ou ainda We desire to put on record ${ }^{17}$. Da mesma forma, existem sentenças em francês que podem ser traduzidas de forma mais enxuta, como Il-y-avait dans cet homme je ne sais quoi de suffisance, em que a tradução exata seria There was in this man I know not what of self-sufficiency ${ }^{18}$. Porém, para ele, a tradução correta seria There was a touch of complacency about him ${ }^{19}$. 0 autor enfatiza que a tradução não deve ser feita pensando na forma como um nativo da língua de origem se comunicaria com o da língua de chegada, mas como um nativo da língua de chegada comunicaria determinada mensagem de forma natural. Em razão disso, o autor usa a palavra "transmutar", alegando que, se necessário, devese transformar sentenças ou parágrafos inteiros.

${ }^{15}$ Tomamos nota, sem comentários adicionais (tradução nossa)

${ }^{16}$ Tomamos nota para referência futura (tradução nossa).

${ }^{17}$ Nós desejamos deixar registrado (tradução nossa).

${ }^{18}$ Havia neste homem um não sei o que de autossuficiência (tradução nossa).

${ }^{19}$ Ele possui um toque de complacência (tradução nossa).
Nós não deveríamos dizer 'Como eu farei este estrangeiro falar Inglês?', mas ' 0 que um inglês teria dito para expressar esta mesma mensagem?' Isto é tradução. Esta é a própria essência da arte: a ressureição de algo estrangeiro em um corpo nativo; não vestido em roupas nativas, mas surgindo da carne e sangue nativos (BELLOC, 1931, p.182, tradução nossa) ${ }^{20}$.

Belloc acrescenta ainda um conselho: nunca embelezar. A menos que se pretenda produzir uma obra de arte de sua autoria, o tradutor não deve ceder à tentação de fazer algo novo que, aos seus olhos, é melhor que o original. As melhores obras feitas pelo homem nunca seriam conhecidas se os tradutores tentassem modificar seu conteúdo com a intenção de melhorá-las, pois já não seriam mais as mesmas. Alguns tradutores sentemse inspirados a fazer algo melhor em sua língua, mas isso não é tradução, é um erro tanto quanto converter algo nobre em algo básico.

No que se refere à tradução em verso e retórica, Belloc considera três regras principais: em primeiro lugar, esse tipo de tradução deve procurar alcançar um efeito espiritual. $\mathrm{O}$ tradutor deve procurar dar ao texto o mesmo efeito, visando alcançar o "espírito" do texto original. Como consequência disso, surge a segunda regra, em que considera que os versos normalmente não devem ser traduzidos em versos, mas em prosa. E, finalmente, a terceira regra, que considera uma regra negativa, na qual o autor aconselha que tradutores devem abandonar o esforço de traduzir o intraduzível.

Quanto ao efeito espiritual mencionado na primeira regra, especialmente em retórica, não há regras para obtê-lo dentro de suas inúmeras formas, mas a regra se aplica ao objetivo: torná-lo objeto supremo. Para o autor, atingir

${ }^{20}$ Do original: We should say to ourselves, not "How shall I make this foreigner talk English?", but "What would an Englishman have said to express this same?" That is translation. That is the very ess "What the art: the resurre the art: the resurection of an alien thing in the giving to it of native flesh and blood. 
esse objetivo é um triunfo e raramente é alcançado. Grandes retóricas e poesias produzem na mente humana um efeito inconfundível, distinto de todas as outras formas. É esse efeito que o tradutor deve arduamente procurar produzir ou, para todos os efeitos, esse é o efeito de que o tradutor deve ao menos tentar se aproximar. É necessário trazer algo "mágico" para o texto, transmitir emoção o mais próximo possível da pretendida pelo texto original, caso contrário, nada foi traduzido.

O autor reconhece que a regra de não traduzir verso em verso é frequentemente transgredida. $\mathrm{O}$ ritmo dos versos tende a inspirar os tradutores a caírem na tentação de reproduzir na sua língua o efeito produzido pela forma rítmica do texto original. Ele concorda que seria melhor traduzir versos em versos, mas segundo ele, é muito mais difícil conseguir transmitir em versos aquilo que certamente se conseguiria fazer em prosa.

Não, não se pode matar o desejo de traduzir verso por verso. Mas não se deve permitir ser conduzido por ele, e deve-se preservar o cânone que, em geral, e principalmente para os mais longos, especialmente para os épicos, o verso deve ser traduzido em prosa (BELLOC, 1931, p.184, tradução nossa) $)^{21}$.

O autor acrescenta que não se deve tentar traduzir o intraduzível. Uma regra que considera negativa e talvez a mais difícil de todas. Explica que se encontrar algo intraduzível e que seu esforço de o traduzir torne o resultado indigno do original, é melhor abandonar o trabalho do que publicá-lo por dois motivos: ao publicar você traduz o autor e não somente a obra, e estará, além disso, expondo seu erro.

${ }^{21}$ Do original: No, one cannot kill the desire to render verse by verse. But one must not let it run away
with one, and one must preserve the canon that in general and especially for the longer flights and with one, and one must preserve the canon that in general and espe

\section{Considerações finais}

Para Hillaire Belloc, uma boa tradução é algo excepcionalmente difícil de alcançar e o talento e a instrução para se chegar a ela são correspondentemente raros. $\mathrm{O}$ autor enfatiza a importância da função social da tradução, sem a qual uma cultura comum não poderia existir. Porém, adverte que, se uma tradução amplamente disseminada na sociedade não for bemfeita, pode fazer mais mal do que bem. Para Belloc, o tradutor pode ser guiado por regras aplicáveis ao trabalho de tradução, e independentemente da função da tradução (instrução ou literária), deve estar livre de restrições mecânicas.

Conforme apontado neste artigo, o conceito de tradução envolve domínios muito diversos e as opiniões entre os autores e as concepções teóricas estão longe de convergir. Toda tradução é uma prática e qualquer teoria que visasse a um receituário ou fórmula estaria, provavelmente, destinada ao insucesso. As considerações de ordem teórica podem ser vistas sob a perspectiva de uma instrumentação a serviço de uma prática, de um fazer e não como um receituário fechado e impositivo.

Todo trabalho de tradução é uma prática que tem a sua especificidade e no decorrer dessa exposição, mostrou-se que a tradução literária, particularmente, leva essa especificidade a limitações ainda mais extremas, sendo julgada, em muitos casos, irrealizável. Nesse campo de estudo, tão complexo e com um terreno ainda muito fértil, parece não ter espaço para radicalizações. Os textos traduzidos estão aí para confirmar. Talvez seja mais seguro, ao invés de afirmar tradutibilidade ou intradutibilidade irrestrita, dizer que existem graus de tradutibilidade, em certos casos maiores, em outros menores.

Tendo exposto esses pontos e considerando meritórias as reflexões de Belloc acerca de questões de tradutologia geral e tradução literária, 
pretende-se que as concepções teóricas e considerações aqui apontadas possam contribuir para a reflexão da prática de tradução ou, ainda, servir como uma significativa instrumentação da prática aos que se propuserem a se empenhar na arte de traduzir.

\section{Referências}

BARTON, Dennis. In Defence of Hilaire Belloc. [S.l.: s.n.], 2014. Disponível em: http://www.churchinhistory.org/pages/booklets/belloc(n).htm. Acesso em: 07 fev. 2019.

BELLOC, Hilaire. On Translation. Oxford: Oxford University Press, 1931.

CATFORD, John C. A Linguistic Theory of Translation. London: OUP, 1965.

DAS, Bijay K. Handbook of Translation Studies. New Delhi: Atlhantic, 2008.

FURLAN, M. (org.). Clássicos da teoria da tradução. Vol. 4. Renascimento. Florianópolis: UFSC/NUPLITT, 2006.

KRISHNASWAMY et al. Modern Applied Linguistics. Madras: MacMillan, 1992.

LARANJEIRA, Mário. Poética da Tradução: do sentido à significância. São Paulo, EDUSP/FAPESP, 1993 (Criação e Crítica).

MILTON, John. O poder da tradução. São Paulo: Ars Poetica, 1993.

MORTON, J. B. Hilaire Belloc. Catholic Book Edition. [S.l.]: Book club, 1955.

NORD, Christiane. Text Analysis in Translation: theory, methodology, and didactic application of a model of translation-oriented text analysis. Tradução Christiane Nord e Penelope Sparrow. Amsterdam, Atlanta: Rodopi, 1991. https://doi. org/10.7202/003387ar

SPEAIGHT, Robert. The Life of Hilaire Belloc. New York: [s.n.], 1957.
WELLS, Herbert. Mr. Belloc objects to "The outline of history". London: Watts\&Co., 1926.

WELLWARTH, George. Special considerations in Drama Translation, Translation Spectrum: Essays in Theory and Practise. New York: M. G. Rox, 1987.

Recebido em: $14 / 10 / 2018$

Aprovado em: 7/2/2019.

Publicado em: 20/6/2019. 